Article

\title{
Solvent Effects on the Spin-Transition in a Series of Fe(II) Dinuclear Triple Helicate Compounds
}

\author{
Alexander R. Craze ${ }^{1}$, Mohan M. Bhadbhade ${ }^{2}$, Cameron J. Kepert ${ }^{3}$, Leonard F. Lindoy ${ }^{3}$, \\ Christopher E. Marjo ${ }^{2}(\mathbb{D})$ and Feng Li $^{1, *} \mathbb{D}$ \\ 1 School of Science and Health, Western Sydney University, Penrith, Sydney, NSW 2751, Australia; \\ 17717986@student.westernsydney.edu.au \\ 2 Mark Wainwright Analytical Centre, University of New South Wales, Sydney, NSW 2052, Australia; \\ m.bhadbhade@unsw.edu.au (M.M.B.); c.marjo@unsw.edu.au (C.E.M.) \\ 3 School of Chemistry, University of Sydney, Sydney, NSW 2006, Australia; \\ cameron.kepert@sydney.edu.au (C.J.K.); len.lindoy@sydney.edu.au (L.F.L.) \\ * Correspondence: Feng.Li@westernsydney.edu.au
}

Received: 11 September 2018; Accepted: 19 September 2018; Published: 23 September 2018

\begin{abstract}
This work explores the effect of lattice solvent on the observed solid-state spin-transition of a previously reported dinuclear $\mathrm{Fe}$ (II) triple helicate series 1-3 of the general form $\left[\mathrm{Fe}^{\mathrm{II}}{ }_{2} \mathbf{L}_{3}\right]\left(\mathrm{BF}_{4}\right)_{4}\left(\mathrm{CH}_{3} \mathrm{CN}\right)_{\mathrm{n}}$, where $\mathbf{L}$ is the Schiff base condensation product of imidazole-4-carbaldehyde with 4,4-diaminodiphenylmethane $\left(\mathbf{L}^{\mathbf{1}}\right), 4,4^{\prime}$-diaminodiphenyl sulfide $\left(\mathbf{L}^{2}\right)$ and 4,4'-diaminodiphenyl ether $\left(\mathbf{L}^{3}\right)$ respectively, and $\mathbf{1}$ is the complex when $\mathbf{L}=\mathbf{L}^{1}, \mathbf{2}$ when $\mathbf{L}=\mathbf{L}^{2}$ and $\mathbf{3}$ when $\mathbf{L}=\mathbf{L}^{3}$ (Craze, A.R.; Sciortino, N.F.; Bhadbhade, M.M.; Kepert, C.J.; Marjo, C.E.; Li, F. Investigation of the Spin Crossover Properties of Three Dinuclear Fe(II) Triple Helicates by Variation of the Steric Nature of the Ligand Type. Inorganics. 2017, $5(4), 62)$. Desolvation of 1 and 2 during measurement resulted not only in a decrease in $\mathrm{T}_{1 / 2}$ and completeness of spin-crossover (SCO) but also a change in the number of steps in the spin-profile. Compounds 1 and $\mathbf{2}$ were observed to change from a two-step $70 \%$ complete transition when fully solvated, to a single-step half complete transition upon desolvation. The average $T_{1 / 2}$ value of the two-steps in the solvated materials was equivalent to the single $\mathrm{T}_{1 / 2}$ of the desolvated sample. Upon solvent loss, the magnetic profile of 3 experienced a transformation from a gradual SCO or weak antiferromagnetic interaction to a single half-complete spin-transition. Variable temperature single-crystal structures are presented and the effects of solvent molecules are also explored crystallographically and via a Hirshfeld surface analysis. The spin-transition profiles of 1-3 may provide further insight into previous discrepancies in dinuclear triple helicate $\mathrm{SCO}$ research reported by the laboratories of Hannon and Gütlich on analogous systems (Tuna, F.; Lees, M. R.; Clarkson, G. J.; Hannon, M. J. Readily Prepared Metallo-Supramolecular Triple Helicates Designed to Exhibit Spin-Crossover Behaviour. Chem. Eur. J. 2004, 10, 5737-5750 and Garcia, Y.; Grunert, C. M.; Reiman, S.; van Campenhoudt, O.; Gütlich, P. The Two-Step Spin Conversion in a Supramolecular Triple Helicate Dinuclear Iron(II) Complex Studied by Mössbauer Spectroscopy. Eur. J. Inorg. Chem. 2006, 3333-3339).
\end{abstract}

Keywords: spin-crossover; dinuclear triple helicate; Fe(II); solvent effects

\section{Introduction}

Spin-crossover (SCO) materials continue to attract a wide degree of multidisciplinary research effort [1-5]. For example, these materials have been demonstrated to show significant promise for use in molecular switches and sensors [6-9]. Such applications stem from the inherent bistability of SCO compounds and the many ways with which this bistability can be altered. For octahedral $\mathrm{Fe}(\mathrm{II})$-based materials, a spin-transition may be induced by temperature, pressure or light between the paramagnetic ${ }^{5} \mathrm{~T}_{2} \mathrm{HS}(\mathrm{S}=2)$ state and the diamagnetic ${ }^{1} \mathrm{~A}_{1} \mathrm{LS}(\mathrm{S}=0)$ state $[2,10,11]$. 
The ability of the spin-transition to be readily altered can be a strong benefit in SCO research, in that factors such as the transition temperature $\left(\mathrm{T}_{1 / 2}\right)$, the number of steps, the completeness of SCO and its abruptness can often be subtly manipulated. On the other hand, such lack of stability can also serve as a distinct problem for these materials when it comes to finding real-world applications. That so many external influences can alter the spin-transition of a compound makes the precise nature of fabricated SCO materials very difficult to predict and control. The extensive and varied effects that solvent(s) of crystallisation have on the properties of SCO materials is a prime example of this $[12,13]$. Thus, it has been extensively shown that the spin-transition can be significantly affected by the intermolecular interactions induced by solvent molecules [14-26]. Solvent molecules of crystallisation can affect the transition temperature $\left(\mathrm{T}_{1 / 2}\right)$ [26-36], the nature of the spin-transition as well as the degree of cooperativity and thermal hysteresis that occurs [12,37-40]. Previous studies have indicated that the elastic interactions between the SCO active metal centres can be enhanced by the formation of hydrogen-bonding networks between solvent and/or anion molecules, leading to abrupt and hysteric spin-transitions [14,15]. Furthermore, solvent molecules can impose different crystal packing arrangements within the lattice, affecting the cooperative interactions between metal centres. Severe structural transformations such as single-crystal-to-single-crystal transformations arising from the exchange of solvent molecules of crystallisation have also been demonstrated [1,41-46]. In some examples, solvent effects can even be reversibly triggered by desolvation and resolvation of the solid material [47-50]. The onset of an apparent hysteresis, in which irreversible changes in the profile are observed, are often induced by the loss of solvent molecules, a process that tends to stabilise the high-spin (HS) state [24,25,51-53]. As a result, there is potential for thermally induced spin-transitions to be 'tuned' by the adsorption and desorption of solvent molecules of crystallisation, leading to a potential application as chemosensors [20,50].

The subtleties of the effects of solvent molecules on the spin-transition phenomenon are highlighted in a study performed by Kruger and co-workers who presented a pair of solvatomorphs of a Fe(II) dinuclear triple helicate structure that demonstrated a half-transition when incorporating water molecules of crystallisation and a full asymmetric spin-crossover when acetonitrile molecules were present in the crystal lattice [51,54]. Two independent studies were performed by Garcia et al. [55] and Neville et al. [56] on two pseudopolymorphs of the complex $\left[\mathrm{Fe}_{2}{ }_{2}(\mathrm{~A})_{5}(\mathrm{cis}-\mathrm{NCS})_{4}\right] \mathrm{nMeOH}$, where $\mathrm{n}=$ 4 and 2 respectively and $\mathbf{A}=N$-salicylidene 4-amino-1,2,4-triazole. The first presented a monoclinic structure with a $\mathrm{T}_{1 / 2}$ of $155 \mathrm{~K}$, while the latter yielded a triclinic structure with no SCO taking place. Despite the formula of these two compounds differing by only two $\mathrm{MeOH}$ solvent molecules, and both polymorphs exhibiting $\pi-\pi$ stacking interactions, vastly dissimilar magnetic properties were obtained.

Previously, we reported the SCO of three desolvated Fe(II) dinuclear triple helicate compounds 1-3, that displayed single-step spin-transitions of ca. 50\% completion [57]. Herein we report the effects of acetonitrile solvent molecules on the spin-transitions in this series of dinuclear triple helicates, which have the general formula $\left[\mathrm{Fe}^{\mathrm{II}}{ }_{2} \mathrm{~L}_{3}\right]\left(\mathrm{BF}_{4}\right)_{4}\left(\mathrm{CH}_{3} \mathrm{CN}\right)_{\mathrm{n}}$ and which differ in the steric nature of $\mathbf{L}$ (Figure 1). For compound $\mathbf{1} \mathbf{L}=\mathbf{L}^{\mathbf{1}}$, for $\mathbf{2} \mathbf{L}=\mathbf{L}^{\mathbf{2}}$ and for $\mathbf{3} \mathbf{L}=\mathrm{L}^{3}$. These compounds exhibit a change in the degree of completeness of SCO as well as a transfer from a two-step to a single-step spin-transition upon desolvation in the case of $\mathbf{1}$ and $\mathbf{2}$. Conversely, $\mathbf{3}$ exhibits an alteration from a gradual SCO (or possibly exhibits weak antiferromagnetic interactions) to a single-step incomplete SCO upon desolvation. Furthermore, the spin-transition profiles observed for 1-3 may provide an interesting insight into a previously reported discrepancy in the literature concerning Fe(II) dinuclear triple helicates presented by both teams of Hannon and Gütlich $[58,59]$. 


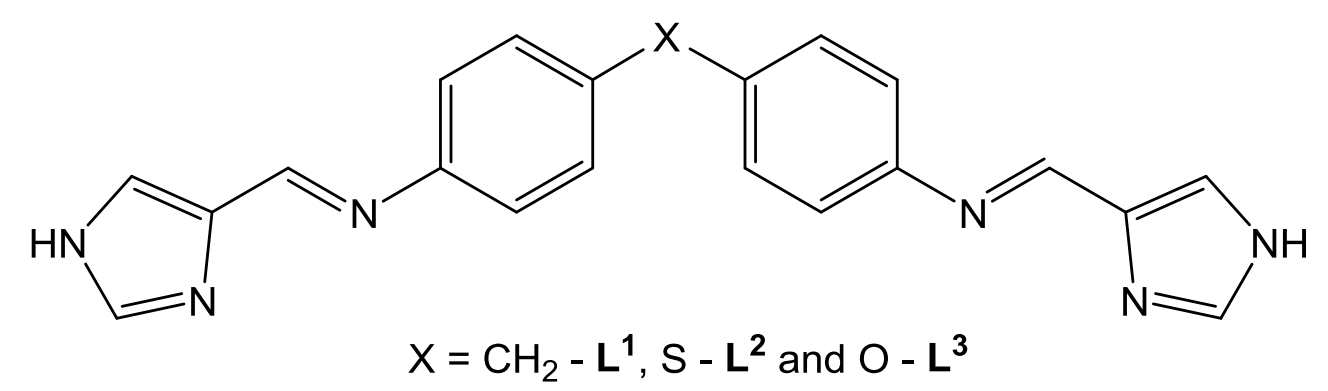

Figure 1. Schematic representation of $\mathrm{L}^{1}, \mathrm{~L}^{2}$ and $\mathrm{L}^{3}$ used to construct the dinuclear triple helicate architectures presented in this study.

\section{Materials and Methods}

All reagents and solvents were purchased from commercial sources (Sigma-Aldrich, Sydney, Australia and Alfa Aesar by Thermo Fisher Scientific, Australia and Tokyo Chemical Industry Co., Ltd., Adelaide, Australia), with no further purification being undertaken. Compounds 1-3 were prepared using the previously reported method [57]. Thermal gravimetric analysis (TGA) measurements were performed using a simultaneous thermal analysis (STA) 449 C Jupiter instrument (NETZSCH, Selb, Germany) using aluminium crucibles, nitrogen was used as both the protective and purge gas; the temperature range of $30-200{ }^{\circ} \mathrm{C}$ was cycled at a rate of $10 \mathrm{~K} \cdot \mathrm{min}^{-1}$.

\subsection{X-ray Crystallography}

The X-ray crystallography experiments were performed on the MX1 beamline at the Australian Synchrotron (Clayton, Victoria, Australia.), using silicon double crystal monochromated radiation $[60,61]$ or using a Bruker kappa-II CCD diffractometer, employing an I $\mu$ S Incoatec Microfocus Source with Mo-K $\alpha$ radiation $(\lambda=0.710723 \AA)$. Data integration and reduction was undertaken with XDS [62] for synchrotron data and with APEX2. Ver. 2014.11-0 and SAINT. Ver. 8.34A (Bruker-AXS, Madison, WI, USA, 2014) [63] for the home source instrument. An empirical absorption correction was then applied using SADABS at the Australian Synchrotron [64]. The structures were solved by direct methods and the full-matrix least-squares refinements were carried out using a suite of SHELX programs (XT. Version 2014/4., XL. Version 2014/7.) [65,66] via the OLEX2 graphical interface [67]. Non-hydrogen atoms were refined anisotropically. Carbon-bound hydrogen atoms were included in idealised positions and refined using a riding model. The crystallographic data in CIF format have been deposited at the Cambridge Crystallographic Data Centre with CCDC 1844792-1844794. It is available free of charge from the Cambridge Crystallographic Data Centre, 12 Union Road, Cambridge CB2 1 EZ, UK; fax: (+44) 1223-336-033; or e-mail: deposit@ccdc.cam.ac.uk. Specific refinement details and crystallographic data for each structure are presented below and in the supporting information.

Powder X-Ray diffraction measurements were conducted on a Bruker D8 ADVANCE diffractometer with a LynxEye position sensitive detector (PSD). The X-ray source was a Copper $\mathrm{K}-\alpha 1$ at $1.54 \AA$ at $40 \mathrm{kV}$ and a current of $40 \mathrm{~mA}$. The sample scan range was 5-55 degrees $2 \theta$ with a step size of $0.02^{\circ}$ at a rate of $2 \mathrm{~s}$ per step. Data processing was conducted using Bruker's EVA software.

\subsection{Magnetic Susceptibility Measurements}

Samples of crystalline material, 1-3, were measured under two separate conditions. First, a solvated sample was sealed in a plastic tube in the presence of mother liquid, with the temperature range reaching a maximum of $300 \mathrm{~K}$ to ensure as little solvent loss as possible during the experiment. Secondly, a filtered sample was placed in an unsealed magnetic sample holder, and the temperature ramped to a maximum of $350 \mathrm{~K}$, allowing desolvation to occur. Data for magnetic susceptibility measurements were collected using a Quantum Design Versalab Measurement System 
(Quantum Design, San Diego, CA, USA) with a vibrating-sample magnetometer (VSM) attachment. Measurements were taken continuously under an applied field of $0.5 \mathrm{~T}$, at a heating rate of $4 \mathrm{~K} \cdot \mathrm{min}^{-1}$.

\subsection{Hirshfeld Surfaces}

The Hirshfeld isosurfaces were calculated using the program Crystal Explorer v17.5 [68].

\section{Results and Discussion}

Magnetic susceptibility studies on polycrystalline samples of 1-3 between 50-350 K demonstrate that these compounds exhibit solvent-dependant SCO (Figure 2). The samples were measured under two separate conditions. First, the solvated solid sample was placed in a plastic tube which was then sealed with some mother liquid. The temperature was increased to a maximum of $300 \mathrm{~K}$ to ensure as little solvent loss as possible from the sample. Secondly, a filtered sample was placed in an unsealed magnetic sample holder and the temperature cycled to a maximum of $350 \mathrm{~K}$, allowing solvent loss. TGA experiments were performed on filtered samples in order to provide evidence of solvent loss within the applied temperature range $\left(30-200{ }^{\circ} \mathrm{C}\right)$ and compare the mass changes due to solvent loss. The filtered samples showed mass losses of 3.33\%, 4.99\% and $4.73 \%$ for 1,2 and 3 respectively when heated to $200{ }^{\circ} \mathrm{C}$ (Figures S4-S6). These mass changes demonstrate that the percentage of weight lost due to desolvation closely matches the mass percentage of acetonitrile present in the asymmetric unit (mass of acetonitrile/total mass $\times 100$ ) at $100 \mathrm{~K}$ calculated from single crystal X-ray diffraction results (for the measurements TGA\%/SCXRD\%-1-3.33/3.92, 2-4.99/4.95, 3-4.73/5.01).

When sealed, 1 underwent a more complete two-step thermally induced spin-transition. The room temperature $\chi_{\mathrm{M}} T$ value was $7.70 \mathrm{~cm}^{3} \cdot \mathrm{K} \cdot \mathrm{mol}^{-1}$, corresponding to two uncoupled $\mathrm{Fe}$ (II) centres in the HS ${ }^{5} \mathrm{~T}_{2}(\mathrm{~S}=2)$ state. Upon cooling, the $\chi_{\mathrm{M}} T$ value decreased steadily, reaching the first $\mathrm{T}_{1 / 2 \downarrow}$ at $205 \mathrm{~K}$. After a minimum rate of change (first derivative) in the magnetic susceptibility at $138 \mathrm{~K}$, the second $\mathrm{T}_{1 / 2 \downarrow}$ occurred at $100 \mathrm{~K}$, after which the susceptibility dropped to a value of $2.13 \mathrm{~cm}^{3} \cdot \mathrm{K} \cdot \mathrm{mol}^{-1}$ at $50 \mathrm{~K}$. At this point, approximately $72 \%$ of $\mathrm{Fe}(\mathrm{II})$ ions have transitioned to the $\mathrm{LS}^{1} \mathrm{~A}_{1}(\mathrm{~S}=0)$ state.

On the other hand, when the sample was run in an unsealed magnetic sample holder and taken to $350 \mathrm{~K}$, allowing the loss of solvent to occur, major changes in the transition profile were observed. In the heating mode, the room temperature magnetic susceptibility remained around $7.70 \mathrm{~cm}^{3} \cdot \mathrm{K} \cdot \mathrm{mol}^{-1}$ and the minimum value was $4.55 \mathrm{~cm}^{3} \cdot \mathrm{K} \cdot \mathrm{mol}^{-1}$ at $50 \mathrm{~K}$, corresponding to only $40 \%$ of the $\mathrm{Fe}$ (II) metal centres undergoing a transition to the $\mathrm{LS}^{1} \mathrm{~A}_{1}$ state at $50 \mathrm{~K}$. The transition occurred in a single-step manner and the $T_{1 / 2 \uparrow}$ was $180 \mathrm{~K}$. In the cooling mode, loss of solvent experienced during the heating mode causes the transition to appear slightly more abrupt in manner, reaching a minimum $\chi_{\mathrm{M}} T$ value of $4.40 \mathrm{~cm}^{3} \cdot \mathrm{K} \cdot \mathrm{mol}^{-1}$ at $50 \mathrm{~K}$ with a $\mathrm{T}_{1 / 2 \downarrow}$ of $155 \mathrm{~K}$.

Similarly, the sealed sample of 2 exhibited a two-step spin-transition, decreasing from a $\chi_{\mathrm{M}} T$ value at $300 \mathrm{~K}$ of $7.55 \mathrm{~cm}^{3} \cdot \mathrm{K} \cdot \mathrm{mol}^{-1}$ to $2.17 \mathrm{~cm}^{3} \cdot \mathrm{K} \cdot \mathrm{mol}^{-1}$ at $50 \mathrm{~K}$, with $\mathrm{T}_{1 / 2 \downarrow}$ of 219 and $135 \mathrm{~K}$ and $\mathrm{T}_{1 / 2 \uparrow}$ of 125 and $209 \mathrm{~K}$ upon thermal cycling. Again, around $72 \%$ of Fe(II) centres present in the material have undergone a spin-transition at this point. When the sample holder was not sealed, the spin transition profile exhibited a very similar trend to that of $\mathbf{1}$, in which only $50 \%$ of the $\mathrm{Fe}$ (II) metal centres had undergone a transition to the $\mathrm{LS}$ state at $50 \mathrm{~K}$ in a single-step manner.

The sealed sample of 3 displayed a room temperature $\chi_{\mathrm{M}} T$ value of $7.70 \mathrm{~cm}^{3} \cdot \mathrm{K} \cdot \mathrm{mol}^{-1}$. This decreases in a steady fashion to $4.27 \mathrm{~cm}^{3} \cdot \mathrm{K} \cdot \mathrm{mol}^{-1}$ at $50 \mathrm{~K}$. The gradual, monotonic decrease in $\chi_{\mathrm{M}} T$ may be interpreted as due to temperature-independent paramagnetism (TIP), weak antiferromagnetic coupling between HS Fe(II) centres or possibly very gradual spin-crossover [69]. On the other hand, the unsealed sample of $\mathbf{3}$ showed a similar shape to that of $\mathbf{1}$ and $\mathbf{2}$ under the same conditions. The heating mode exhibited a $50 \mathrm{~K} \chi_{\mathrm{M}} T$ value of $3.76 \mathrm{~cm}^{3} \cdot \mathrm{K} \cdot \mathrm{mol}^{-1}$, which steadily increased over the range of $50 \mathrm{~K}$ to $350 \mathrm{~K}$, at which point the magnetic susceptibility was $7.65 \mathrm{~cm}^{3} \cdot \mathrm{K} \cdot \mathrm{mol}^{-1}$, demonstrating an inflexion point $\left(\mathrm{T}_{1 / 2}\right)$ at $182 \mathrm{~K}$. At $50 \mathrm{~K}$ the spin-transition is incomplete, with ca. half of the $\mathrm{Fe}(\mathrm{II})$ centres remaining HS. The proceeding cooling mode demonstrated similar room temperature and $50 \mathrm{~K}$ 
$\chi_{\mathrm{M}} T$ values, although it occurred in a seemingly more abrupt fashion, again due to loss of solvent, with a $\mathrm{T}_{1 / 2}$ value of $140 \mathrm{~K}, 42 \mathrm{~K}$ lower than that of the preceding heating mode.
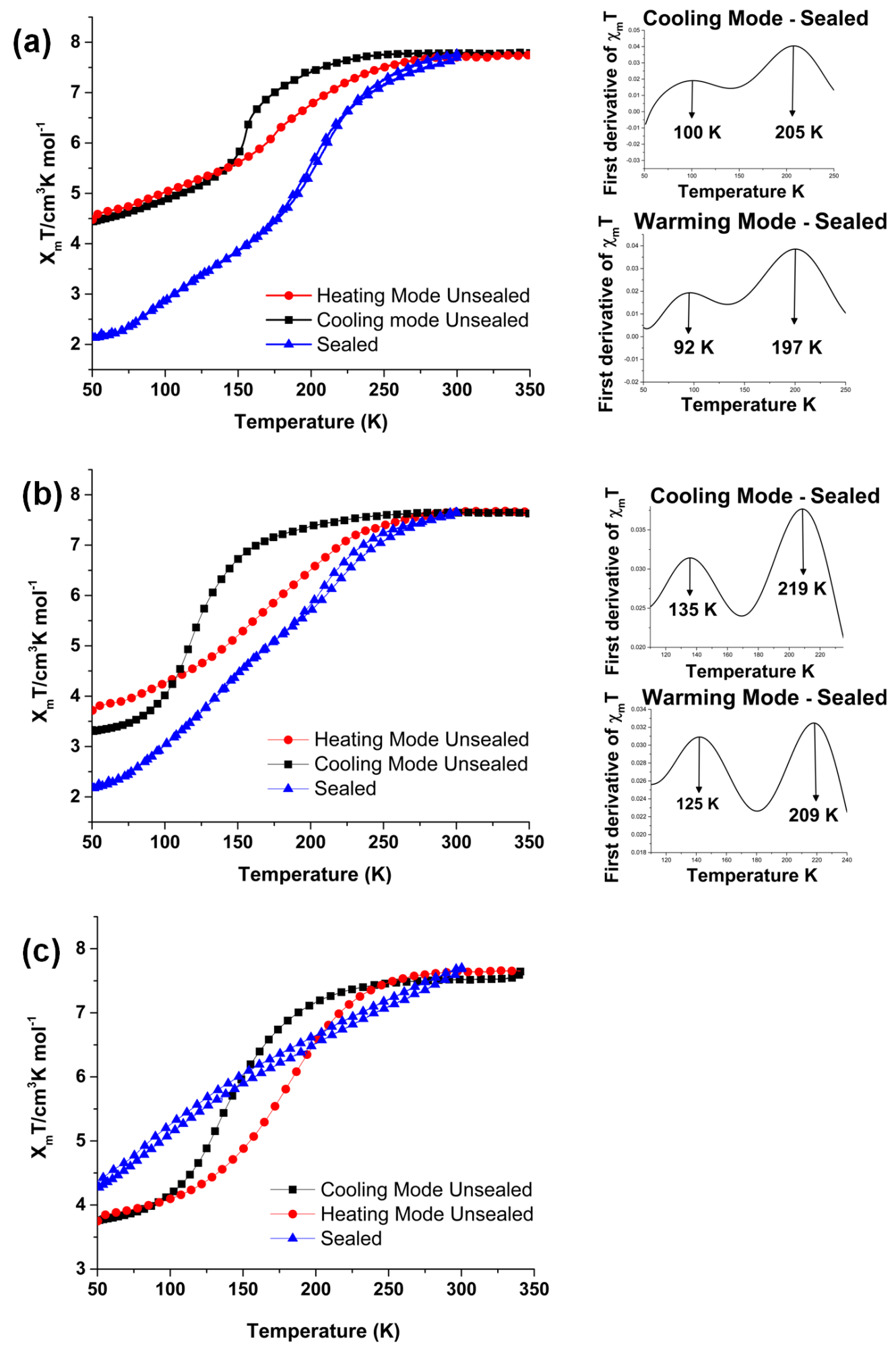

Figure 2. Magnetic susceptibility $\chi_{\mathrm{M}} T$ versus $T$ plots for $1-3,(\mathbf{a}-\mathbf{c})$ respectively, at a scan rate of $4 \mathrm{~K} / \mathrm{min}$ over the temperature range of 50-300 K (solvated) and 50-350 K (desolvated). Inserts for 1 and 2 display the rate of change (first derivative) of the $\chi_{M} T$ value in the sealed samples. 
For $\mathbf{1}$ and 2, the sealed samples both demonstrated a more complete (70\%) two-step transition, whilst the unsealed samples of all three compounds demonstrated a one-step half-completed SCO. For all three compounds, the loss of solvent in the unsealed samples results in a shift in the $T_{1 / 2}$ to lower temperatures, which has also been the case in other solvent sensitive materials. A study performed by Kruger and co-workers [51] on a 2-positioned methylated imidazole donor helicate $\left(\mathrm{ClO}_{4}{ }^{-}\right.$salt), an architecture similar to 3 , showed an analogous trend to those obtained for unsealed samples of $\mathbf{1}, \mathbf{2}$ and $\mathbf{3}$. Here the $\mathrm{T}_{1 / 2}$ moved to a lower temperature with solvent loss (water molecules in this case) and a more abrupt spin-transition occurred. Although on the other hand, the extent of the HS $\leftrightarrow$ LS conversion (completeness) and the nature of the transition-profile (the number of steps) remained the same.

\section{Magneto-structural Correlations}

The single-crystal X-ray diffraction results at $100 \mathrm{~K}$ for $\mathbf{1 - 3}$ were presented in our previous report of the magnetic properties exhibited by completely dried samples [57]. Here, variable temperature single-crystal structures are presented in order to further explore the magneto-structural characteristics of these compounds. The structures of $\mathbf{1}$ and $\mathbf{3}$ at $298 \mathrm{~K}$ as well as $\mathbf{2}$ at $155 \mathrm{~K}$ were obtained in an attempt to further probe the spin-transitions occurring in these compounds. Desolvated samples were not suitable to be measured by single-crystal diffraction. Furthermore, powder X-ray diffraction (PXRD) patterns presented in the supporting information confirm that the synthesised materials retain high crystallinity at room temperature and show good correlation with single-crystal X-ray diffraction (SCXRD) data suggesting that phase purity is maintained at the compared temperatures (Figures S1-S3).

For a full structural description of $\mathbf{1}$ at $100 \mathrm{~K}$, for which a solvatomorph was previously reported by Hannon and co-workers [58], see our previous study mentioned above [57]; a crystallographic summary of the variable temperature SCXRD analysis of 1-3 can be found in Table 1 below and further crystallographic details can be found in the supporting information (Tables S1-S3). At $298 \mathrm{~K}$, 1 presents triclinic symmetry crystallising in the space group $P \overline{1}$. Hydrogen-bonding between $\mathrm{BF}_{4}{ }^{-}$ counter ions and the $\mathrm{N}-\mathrm{H}$ donors of the non-coordinating 2,4-imidazole nitrogen atom is present for four of the six imidazole moieties of the helicate architecture. Similar to the $100 \mathrm{~K}$ structure, no supramolecular network of intermolecular interactions connects adjacent helicates within the crystal lattice. Crystallographic parameters at $298 \mathrm{~K}\left(\sum=\mathrm{Fe} 01-84.84\right.$ and $\mathrm{Fe} 02-84.90^{\circ}$, and average Fe- $\mathrm{N}$ = Fe01-2.21 and Fe02-2.19 $\AA$ ) are in accord with the magnetic susceptibility measurements, indicating that the $\mathrm{Fe}$ (II) centres are present in the [HS-HS] state at room temperature. The two-step nature of the spin-transition for the solvated sample may be a result of the observed monoclinic to triclinic single-crystal-to-single-crystal symmetry breaking that occurs between 100 and $298 \mathrm{~K}$.

Single-crystals of 2 were found to be of triclinic $P \overline{1}$ symmetry at $155 \mathrm{~K}$, crystallising in the same space group as at $100 \mathrm{~K}$. Hydrogen-bonding between imidazole $\mathrm{N}-\mathrm{H}, \mathrm{BF}_{4}{ }^{-}$anions and acetonitrile solvent molecules connects adjacent helicates from both ends along the crystallographic $a$-axis, so as to arrange neighbouring helicates in a side-on manner (Figure 3). Both acetonitrile molecules present in the asymmetric unit interact through hydrogen-bonding $\left(\mathrm{CH}_{3} \mathrm{CN} \cdots \mathrm{H}-\mathrm{N}\right)$ with the non-coordinating nitrogen of the imidazole moiety, with contact lengths of 2.91 and $2.89 \AA$ A. The loss of such interactions in the desolvated material may, therefore, contribute to destabilisation of the [LS-LS] state. The measured octahedral distortions $\left(\sum\right)$ of 60.7 and $92.68^{\circ}$ for $\mathrm{Fe} 01$ and $\mathrm{Fe} 02$ respectively, in conjunction with average Fe-N coordination bond lengths of 2.00 and $2.18 \AA$ for Fe 01 and Fe02, confirm the results of magnetic susceptibility measurements for the solvated sample, and suggest that the helicates are present as the [LS-HS] spin-isomer at this temperature. Single-crystal measurements of $\mathbf{2}$ could not be obtained at higher temperatures. Room temperature PXRD indicates that at $155 \mathrm{~K}$ and $298 \mathrm{~K}$ the material is of the same phase, with no change in symmetry occurring despite the two-step magnetic susceptibility profile (Figure S2).

Alternatively, in contrast to the $100 \mathrm{~K}$ structure which crystallises in the triclinic space group $P \overline{1}$, at $298 \mathrm{~K}, 3$ crystallises in the monoclinic space group $C 2 / c$. Tetrafluoroborate anions participate in 
hydrogen-bonding with each of the six helicate imidazole moieties, forming lengthwise end-to-end intermolecular contacts between adjacent helicates along the crystallographic c-axis (Figure 4). Acetonitrile solvent molecules of 0.5 and 0.25 site occupancy are present in the unit cell but do not participate in any intermolecular interactions. The degree of octahedral distortion was $87.81^{\circ}$ and the average Fe-N distance was $2.20 \AA$, which in combination with magnetic measurements is in accord with the $\mathrm{Fe}(\mathrm{II})$ centres being in the [HS-HS] state at $298 \mathrm{~K}$.

In the solvated samples of $\mathbf{1}$ and $\mathbf{2}$, a more complete, two-step spin-transition occurs from the [HS-HS] state to the [LS-LS] state. Loss of solvent molecules from the crystal lattice was observed to destabilise the [LS-LS] state, trapping the material in a state of either [LS-HS] helicates or a 50:50 mixture of [HS-HS] and [LS-LS] compounds. This suggests that the solvent plays an integral role in the transition of $\mathrm{Fe}$ (II) centres from [HS-HS] $\leftrightarrow$ [LS-LS] in these compounds. In contrast, the loss of acetonitrile from the lattice of 3 induces an incomplete spin-transition, while the solvated sample only gave a gradual and linear change in $\chi_{\mathrm{M}} T$ with temperature, rather than the typical sigmoidal shape indicative of $\mathrm{SCO}$. The desolvation of 3 , acts as a form of 'on-switch' for spin-crossover in this compound.

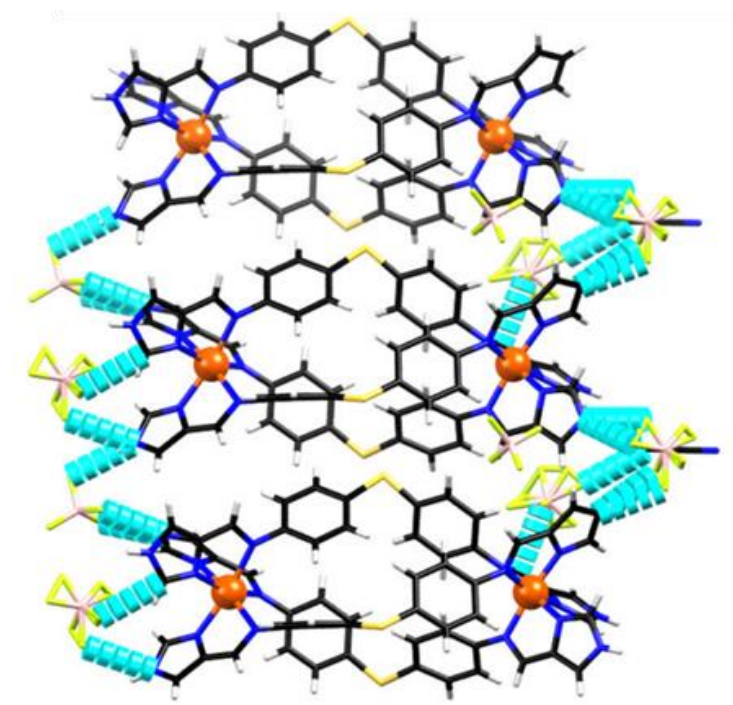

(a)

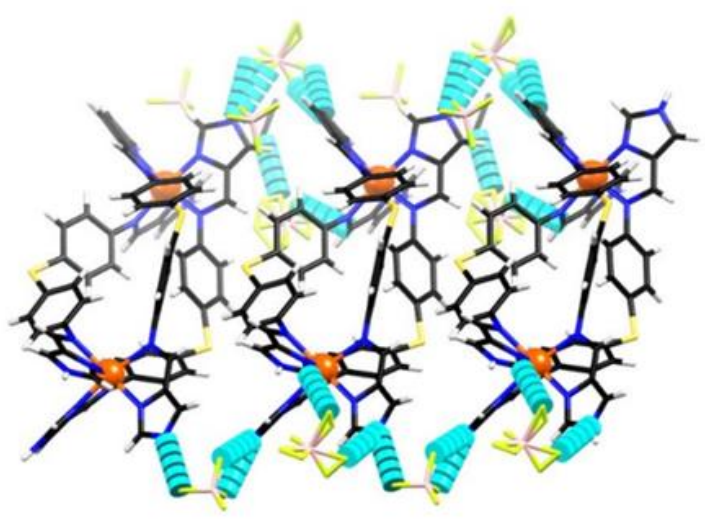

(b)

Figure 3. Schematic representations of the crystal packing and hydrogen-bonding $\left(\mathrm{N}-\mathrm{H}^{\cdots} \mathrm{BF}_{4}{ }^{-}\right)$ interactions present in the single-crystal structure of 2 at $155 \mathrm{~K}$, demonstrating the manner with which adjacent helicates are connected in a side-on manner along the $a$-axis. (a) Projection down the crystallographic $b$-axis and (b) down the $c$-axis. Solvent molecules have been excluded for clarity. Hydrogen bonds are represented by thickened blue dotted lines.

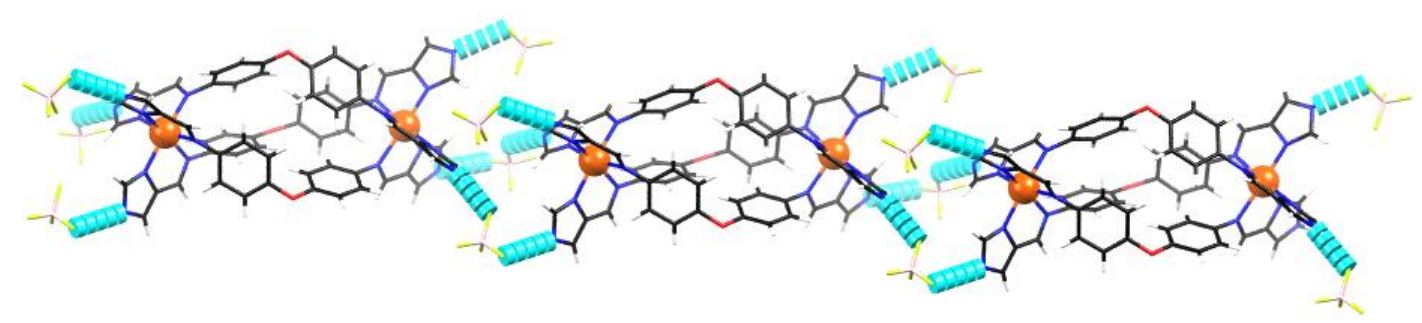

Figure 4. Schematic representation of the crystal packing arrangement of 3 at $298 \mathrm{~K}$, demonstrating the network of hydrogen-bonding interactions that connect the helicates lengthwise along the crystallographic c-axis. 
As illustrated in Figure 5, other parameters that have been used in this study to rationalise the role of intermolecular interactions and intramolecular ligand distortions in the SCO of these compounds, are the angles $\theta_{\text {intermolecular }}$ and $\theta_{\text {intramolecular. }}$ In compounds 1-3, there are three angles connecting the three interior imine nitrogen donors and the Fe(II) centre, and another three connecting the exterior imidazole nitrogen donors and the $\mathrm{Fe}(\mathrm{II})$ centre. The interior angles represent intramolecular distortions, while the exterior angles represent intermolecular distortions. These pairs of three exterior and interior angles $(\phi)$ are each individually subtracted from 90 and the absolute values are summed to give one distortion value for each pair $\left(\theta_{\text {intermolecular }}\right.$ and $\theta_{\text {intramolecular }}$ in Table 2$)$. These parameters were used to further document the effects of intermolecular interactions and intramolecular restraints on the distortion of the SCO coordination sphere.

In all three compounds, differences between the exterior distortions $\left(\Delta \theta_{\text {intermolecular }}\right)$ of the HS and LS/MS Fe(II) centres are consistently more severe than those of the interior distortions ( $\Delta$ $\left.\theta_{\text {intramolecular }}\right)$. In other words, the largest geometric difference between the two centres of opposite spin is at the exterior of the helicate, indicating either that steric restraints imposed by the dinuclear triple helicate architecture are most severe at the interior of the molecule, or that intermolecular interactions may have an important role in accommodating the distortions required to reach the [LS-LS] state. Subsequently, the loss of solvent molecules upon desolvation may hinder the possibility of these necessary molecular rearrangements occurring, as observed in the stabilisation of the [LS-HS] state upon desolvation in both $\mathbf{1}$ and 2.

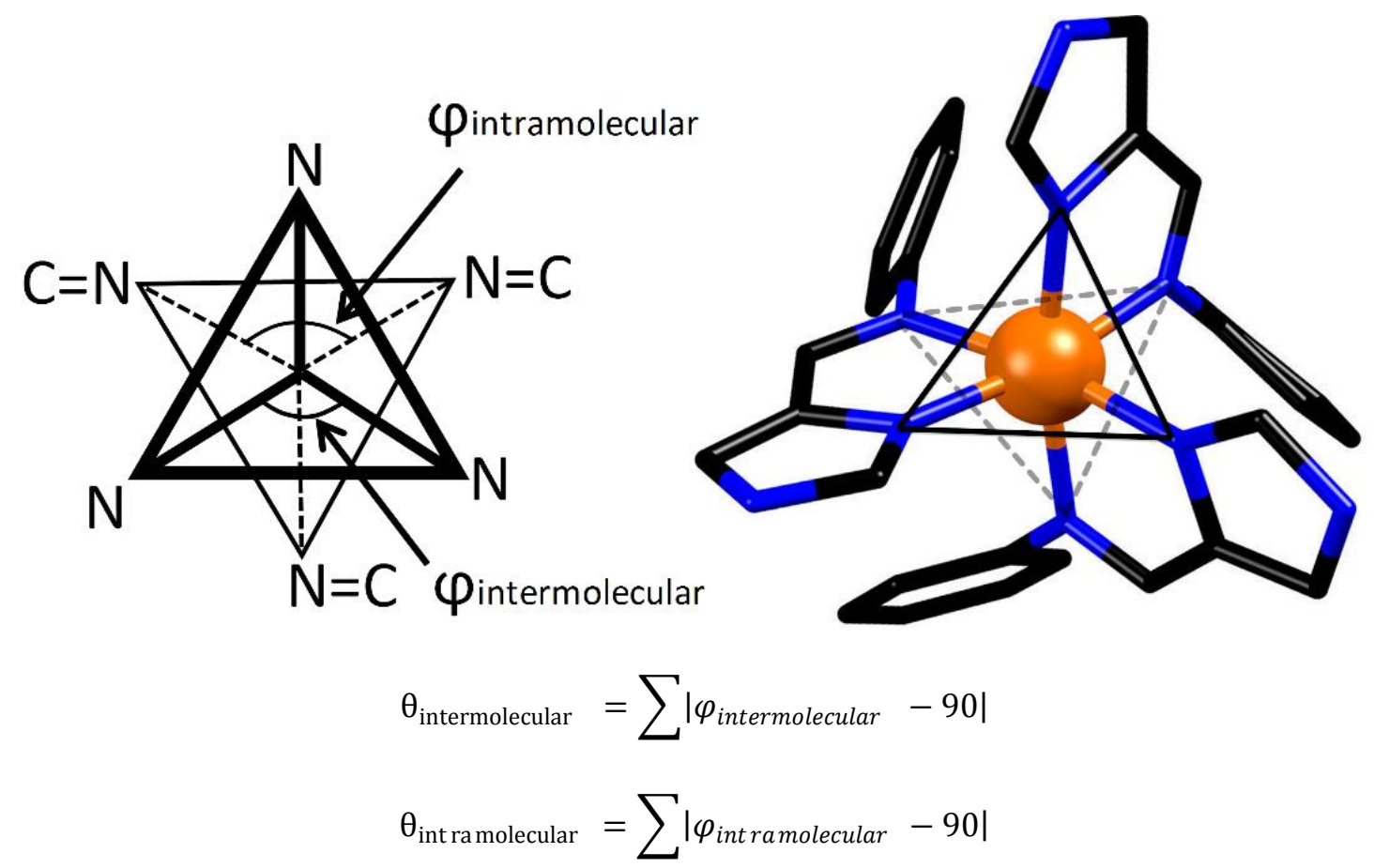

Figure 5. Schematic representation of the two geometric parameters $\theta_{\text {intermolecular }}$ and $\theta_{\text {intramolecular }}$ discussed in the text. 
Table 1. Selected crystallographic parameters for 1, 2 and 3. MS represents a mixed HS/LS state population.

\begin{tabular}{|c|c|c|c|c|c|c|}
\hline \multirow[b]{2}{*}{$\Sigma$} & \multicolumn{2}{|c|}{1} & \multicolumn{2}{|c|}{2} & \multicolumn{2}{|c|}{3} \\
\hline & $\begin{array}{c}100 \mathrm{~K} \\
\mathrm{Fe} 01-76.3\end{array}$ & $\begin{array}{c}298 \mathrm{~K} \\
\mathrm{Fe} 01-84.8 \\
\mathrm{Fe} 02-84.9\end{array}$ & $\begin{array}{c}100 \mathrm{~K} \\
\mathrm{Fe} 01-59.4 \\
\mathrm{Fe} 02-90.3\end{array}$ & $\begin{array}{c}155 \mathrm{~K} \\
\mathrm{Fe} 01-60.4 \\
\mathrm{Fe} 02-92.7\end{array}$ & $\begin{array}{c}100 \mathrm{~K} \\
\mathrm{Fe} 01-77.2 \\
\mathrm{Fe} 02-85.2\end{array}$ & $\begin{array}{c}298 \mathrm{~K} \\
\mathrm{Fe} 01-87.5\end{array}$ \\
\hline $\begin{array}{l}\text { Average } \mathrm{Fe}(\mathrm{II})-\mathrm{N} \\
\text { distance }(\AA)\end{array}$ & Fe01-2.13 & $\begin{array}{l}\mathrm{Fe} 01-2.21 \\
\mathrm{Fe} 02-2.19\end{array}$ & $\begin{array}{l}\mathrm{Fe} 01-2.00 \\
\mathrm{Fe} 02-2.18\end{array}$ & $\begin{array}{l}\mathrm{Fe} 01-2.00 \\
\mathrm{Fe} 02-2.18\end{array}$ & $\begin{array}{l}\mathrm{Fe} 01-2.10 \\
\mathrm{Fe} 02-2.18\end{array}$ & 2.20 \\
\hline Spin state of Fe(II) & MS & HS-HS & LS-HS & LS-HS & HS-MS & HS \\
\hline $\begin{array}{c}\theta_{\text {intermolecular }} / \theta_{\text {intramolecular }} \\
100 \mathrm{~K}\end{array}$ & Fe01-15.4/15.3 & $\begin{array}{l}\text { Fe01-23.8/20.6 } \\
\text { Fe02-18.6/16.4 }\end{array}$ & $\begin{array}{l}\mathrm{Fe} 01-1.6 / 21.0 \\
\mathrm{Fe} 02-6.1 / 23.9\end{array}$ & $\begin{array}{l}\text { Fe01-1.75/23.407 } \\
\text { Fe02-6.731/26.834 }\end{array}$ & $\begin{array}{l}\text { Fe01-19.6/11.1 } \\
\text { Fe02-14.8/13.1 }\end{array}$ & $20.6 / 10.7$ \\
\hline Space group & $C 2 / c$ & $P \overline{1}$ & $P \overline{1}$ & $P \overline{1}$ & $P \overline{1}$ & $C 2 / c$ \\
\hline $\begin{array}{l}\text { Intermolecular } \\
\text { interactions }\end{array}$ & $\begin{array}{c}6 \times \mathrm{N}-\mathrm{H}^{\cdots} \mathrm{BF}_{4}^{-} \\
\mathrm{F}_{3} \mathrm{BF} \cdots \mathrm{H}-\mathrm{CH}_{2} \mathrm{C}-\mathrm{N} \\
\text { No supramolecular } \\
\text { network present }\end{array}$ & $\begin{array}{c}4 \times \mathrm{N}-\mathrm{H}^{\cdots} \mathrm{BF}_{4}^{-} \\
\text {No supramolecular } \\
\text { network present }\end{array}$ & $\begin{array}{l}2 \times \mathrm{N}-\mathrm{H}^{\cdots} \mathrm{CH}_{3} \mathrm{CN} \\
4 \times \mathrm{N}-\mathrm{H}^{\cdots} \mathrm{BF}_{4}^{-} \\
\text {Form side-ways chain }\end{array}$ & $\begin{array}{c}2 \times \mathrm{N}-\mathrm{H} \cdots \mathrm{CH}_{3} \mathrm{CN} \\
4 \times \mathrm{N}-\mathrm{H} \cdots \mathrm{BF}_{4}^{-} \\
\text {Form side-ways chain }\end{array}$ & $\begin{array}{l}6 \times \mathrm{N}-\mathrm{H} \cdots \mathrm{BF}_{4}^{-} \\
\text {Form length-wise } \\
\text { chain }\end{array}$ & $\begin{array}{c}6 \times \mathrm{N}-\mathrm{H}^{\cdots} \mathrm{BF}_{4}^{-} \\
\text {Form length-wise } \\
\text { chain }\end{array}$ \\
\hline $\begin{array}{l}\text { Number of } \\
\text { intramolecular } \\
\text { edge-to-face } \pi \\
\text { interactions }\end{array}$ & 3 & 2 & 3 & 3 & 2 & 2 \\
\hline $\begin{array}{l}\text { Number of acetonitrile } \\
\text { solvent molecules }\end{array}$ & 1.5 & 1.25 & 2 & 2 & 2 & 0.75 \\
\hline $\begin{array}{l}\mathrm{C}-\mathrm{X}-\mathrm{C} \text { angle (where } \mathrm{X} \\
\left.\quad=\mathrm{CH}_{2}, \mathrm{~S} \text { or } \mathrm{O}\right)\end{array}$ & 113.6 & 115.4 & 104.9 & 105.1 & 115.8 & 116.2 \\
\hline $\begin{array}{l}\text { Intrahelical-separation } \\
(\AA)\end{array}$ & 11.72 & 11.72 & 11.78 & 11.77 & 11.62 & 11.72 \\
\hline
\end{tabular}

Source: Note: the three $100 \mathrm{~K}$ structures have been reported previously [57].

Table 2. Comparison of the internal ( $\left.\theta_{\text {intramolecular }}\right)$ and external $\left(\theta_{\text {intermolecular }}\right)$ distortions of the Fe(II) coordination environment in the different spin-states observed for 1, 2 and 3 . MS denotes a mixed HS/LS-state population. The $\Delta \theta$ values represent the differences between the LS (or MS) and HS $\theta$ values in each structure.

\begin{tabular}{cccccc}
\hline Compound & Spin-State & $\theta_{\text {intermolecular }}$ & $\Delta \theta_{\text {intermolecular }}$ & $\theta_{\text {intramolecular }}$ & $\Delta \theta_{\text {intramolecular }}$ \\
\hline \multirow{2}{*}{1} & MS & 15.439 & 8.347 & 15.252 & 5.418 \\
& HS & 23.786 & & 20.61 & \\
2 & LS & 1.57 & 4.554 & 21.047 & 2.847 \\
& HS & 6.124 & & 11.05 & 2.079 \\
\hline
\end{tabular}

The role of these intermolecular interactions can be visualised utilising Hirshfeld surfaces [21,70]. Any electron density within the isosurface predominantly consists of the contribution of the considered molecule, while that outside the surface is dominated by the remainder of the crystal lattice. The parameter $d_{\text {norm }}$ is useful in visualising significant intermolecular interactions and is composed of two parameters that describe the distance an atom is from the isosurface, $d_{\mathrm{i}}$, if the atom is inside the surface, and $d_{\mathrm{e}}$ if the atom is outside [71]. The parameter $d_{\text {norm }}$ returns a zero value when the sum of $d_{\mathrm{i}}$ and $d_{\mathrm{e}}$ equates to the sum of the van der Waals radii of the atoms in question. Strong intermolecular interactions are represented as red areas on the Hirschfield surface, and signify regions in which the value of $d_{\text {norm }}$ is negative and the sum of $d_{\mathrm{i}}$ and $d_{\mathrm{e}}$ is less than the sum of the van der Waals radii. The Hirshfeld plots shown in Figure 6 are calculated for 2 at $100 \mathrm{~K}$ using the program Crystal Explorer [68]. The Hirshfeld surface of 2 displays red regions of the isosurface representing the hydrogen-bonding at the imidazole $\mathrm{N}-\mathrm{H}$ donor site between acetonitrile solvent molecules and $\mathrm{BF}_{4}{ }^{-}$ anions respectively. When the isosurface is analysed with respect to the crystal packing of 2 (Figure 7), it can be observed that the anions and solvent molecules form a network of hydrogen-bonding along this row of helicates ( $a$-axis). The helicates orientate themselves in the lattice so as to offset the regions of strongest intermolecular interactions relative to their neighbouring molecules. These surfaces demonstrate the role of such interactions in providing a network of intermolecular contacts between adjacent helicates, and, as a result, how the loss of the solvent molecules of crystallisation in the desolvated samples results in the destabilisation of the [LS-LS] state. 


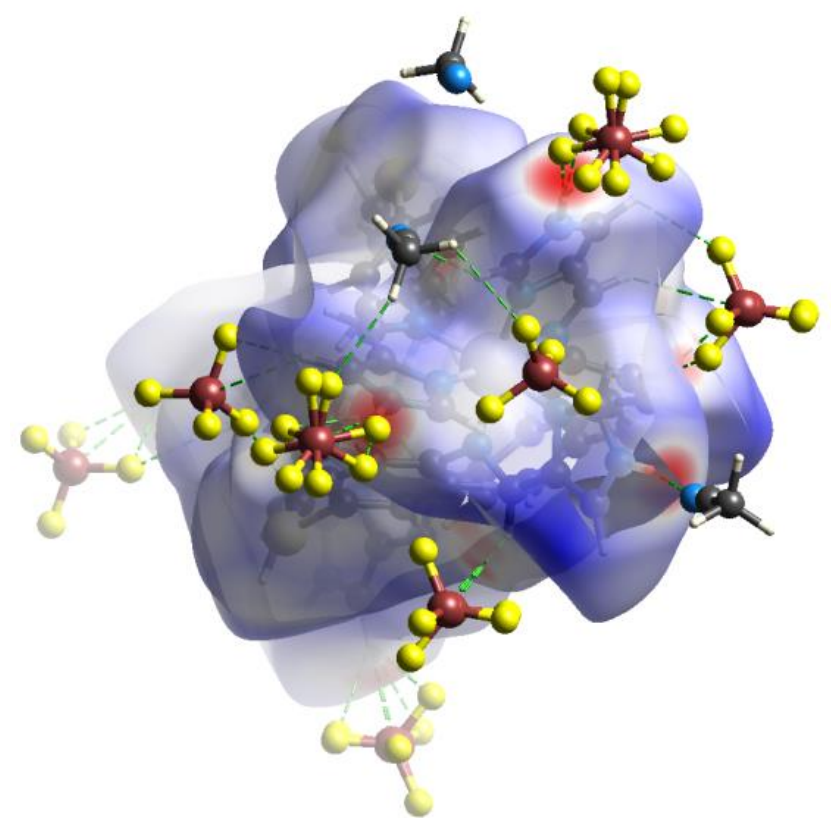

Figure 6. Hirshfeld surface of 2 at $100 \mathrm{~K}$, showing the strongest intermolecular contacts in red located at the three external imidazole N-H groups at each end of the helicate, demonstrating the interactions between helicates, solvent and counterions.

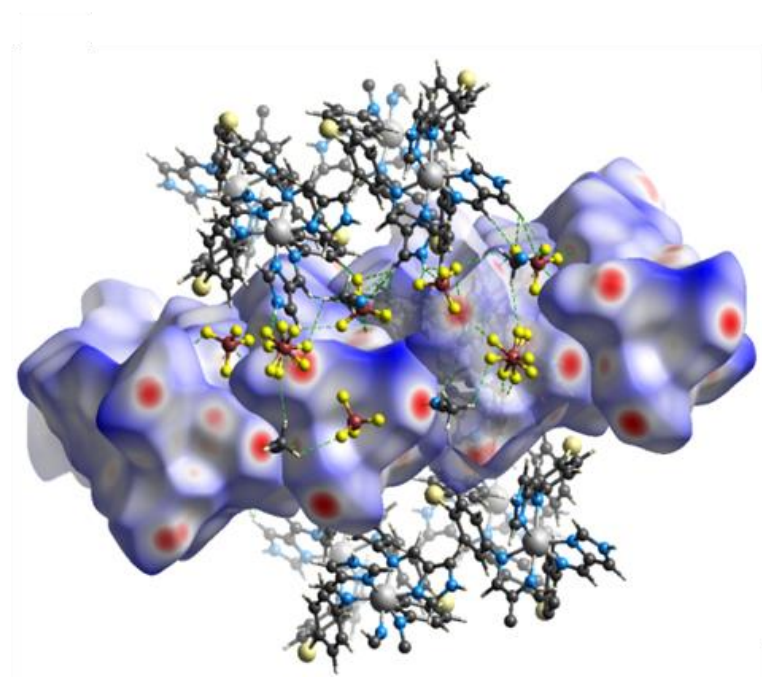

(a)

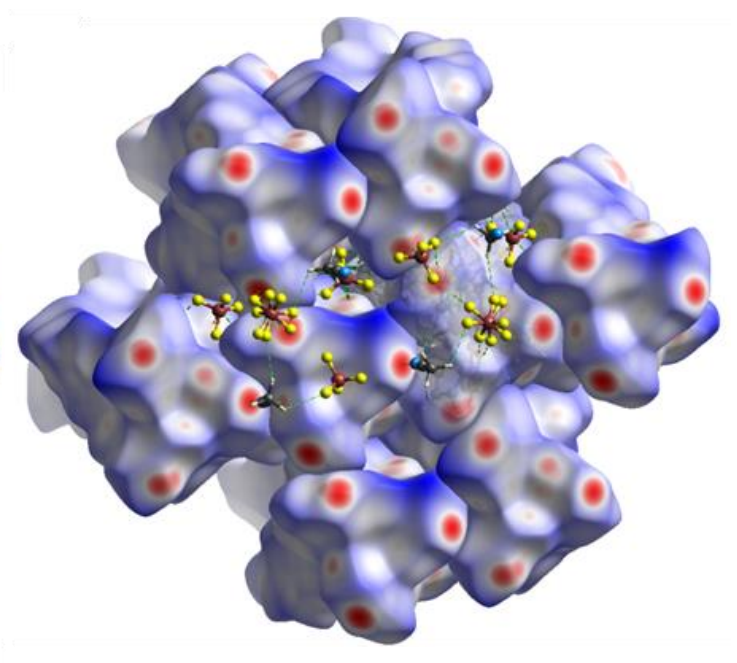

(b)

Figure 7. Hirshfeld surface within the crystal lattice of 2, highlighting the interactions between the helicates, solvent and counter ions that connect adjacent helicates along the crystallographic $a$-axis. The strongest intermolecular contacts are denoted by surface regions shown in red. (a) reveals two rows of helicates with no isosurface (top and bottom) for clarity, while (b) depicts these surfaces.

The change in octahedral distortion $\left(\sum\right)$ between the LS and HS centres in helicates 1-3 is around $30^{\circ}$ (Table 1), and when considered over two Fe(II) centres in the one compound, this places quite a significant strain on each semi-rigid helicate architecture. The overlap figure below (Figure 8) shows 3 at $100 \mathrm{~K}$ and $298 \mathrm{~K}$, and demonstrates the significant change in helicate architecture between the [HS-HS] and [LS-HS] structures, which may also help to rationalise the occurrence of the incomplete spin-transition observed. The majority of SCO dinuclear triple helicates reported previously exhibit such incompleteness, and, to the best of our knowledge, only the systems of Kruger and co-workers [54,72] as well as our laboratory [73] display a full transition of the two $\mathrm{Fe}$ (II) 
sites of the dinuclear triple helicate architecture. The distortion required of the two spin-centres in semi-rigid dinuclear triple helicates makes a complete [HS-HS] $\leftrightarrow[\mathrm{LS}-\mathrm{LS}]$ transition difficult to achieve. That is, these compounds may be trapped in the [LS-HS] state by intramolecular steric constraints. Although, the presence of solvent molecules in $\mathbf{1}$ and $\mathbf{2}$ results in a two-step $70 \%$ complete spin-transition that does partially access the [LS-LS] state. Therefore, intermolecular interactions mediated by solvent molecules may influence the ability of $\mathbf{1}$ and $\mathbf{2}$ to achieve SCO at the second $\mathrm{Fe}$ (II) centre and to access a [LS-LS] state.

(a)

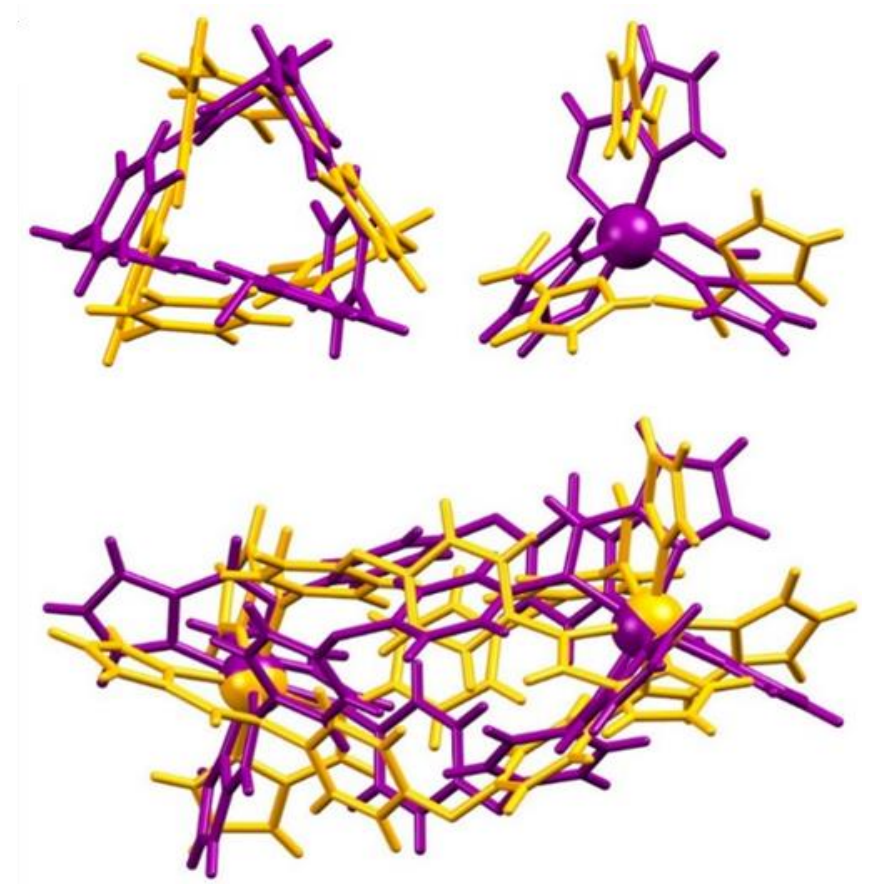

(c)

Figure 8. Schematic showing the overlapping representations of 3 at $100 \mathrm{~K}$ (purple) and $298 \mathrm{~K}$ (orange), illustrating the severity of distortion occurring between the [LS-HS] and [HS-HS] spin-isomers. (a) focuses on the change in the internal ring sections of the helicate ligands, (b) the external imidazoleimine groups, and (c) shows the overall change in conformation relative to the $\mathrm{Fe} \cdots$ Fe positions.

Hannon and co-workers conducted a study of a complex using the same helicate architecture as $\mathbf{1}$, in which they investigated the effect of different counter ions, namely $\mathrm{PF}_{6}{ }^{-}, \mathrm{BF}_{4}{ }^{-}$and $\mathrm{ClO}_{4}{ }^{-}$, being present [58]. The $\left[\mathrm{Fe}_{2}(\mathrm{~L})_{3}\left[\mathrm{ClO}_{4}\right]_{4}\right.$ structure they obtained displayed a gradual, incomplete single-step transition like the desolvated samples in our previous study [57] and also the unsealed samples in this study. A later study by Gütlich and co-workers further explored the $\mathrm{ClO}_{4}{ }^{-}$salt of this compound that led to an in-depth analysis of its magnetic behaviour and Mössbauer spectra [59]. Interestingly, these latter workers found a two-step spin-transition, where the average transition temperature of around $180 \mathrm{~K}$ corresponded to the $\mathrm{T}_{1 / 2}$ of the gradual spin-transition presented by Hannon. The data presented by Gütlich and co-workers was cycled between 300-1.8 K, while that of Hannon and co-workers was cycled between $340-1.8 \mathrm{~K}$, with acetonitrile being the solvent of crystallisation in each case. Heating to $300 \mathrm{~K}$ may not be sufficient for significant loss of solvent of crystallisation, whereas heating to $340 \mathrm{~K}$ would likely be sufficient, in accord with our TGA analysis of the $\mathrm{BF}_{4}{ }^{-}$analogue, 1 (Figures S4-S6). In other words, it appears that the sample of Hannon and co-workers may have desolvated, while that of Gütlich remained solvated to a greater extent. In the present study of a $\mathrm{BF}_{4}{ }^{-}$analogue of those compounds just mentioned, 1, together with two similar helicates, $\mathbf{2}$ and 3, differing in the steric nature 
of their ligands (L), we found that both $\mathbf{1}$ and $\mathbf{2}$ behaved in a similar manner to that described by Hannon and Gütlich in combination. That is, when the helicate samples are completely solvated, they exhibit a gradual two-step spin-crossover, while conversely, when each sample is heated and desolvated, each exhibits a gradual single-step transition where the average $T_{1 / 2}$ of the two-step transition is very close to the $\mathrm{T}_{1 / 2}$ of the single-step transition present in the desolvated sample. This highlights the importance of solvent effects on SCO in the solid-state and further highlights the effects of sample preparation and experimental procedure on the observed spin-transition.

\section{Conclusions}

For all three compounds investigated, the partial desolvation of the sample during the magnetic measurements resulted in a decreased $\mathrm{T}_{1 / 2}$ and a change in the completeness of transition. Compounds 1 and 2 demonstrated a two-step 70\% complete profile when solvated and a single-step half-complete profile when desolvated. In this way, the solvent molecules of crystallisation may help to partially access the [LS-LS] state in $\mathbf{1}$ and $\mathbf{2}$. Solvated samples of $\mathbf{3}$ displayed a monotonic decrease in magnetic susceptibility with temperature, indicative of either a gradual SCO or antiferromagnetic interactions between Fe(II) centres, while the desolvated samples exhibited an approximately $50 \%$ complete gradual spin-transition. The results may provide some insight into previous differences reported in the literature for dinuclear Fe(II) triple helicates by the groups of Hannon and Gütlich, as well as demonstrating the impact of solvent molecules of crystallisation on the SCO in these systems. The study also serves to further highlight the importance of sample preparation and experimental procedure when undertaking magnetic susceptibility measurements with solvent sensitive materials.

Supplementary Materials: The following are available online at http:/ / www.mdpi.com/2073-4352/8/10/376/s1, Figure S1: PXRD pattern of 1, with the $298 \mathrm{~K}$ PXRD pattern in black on top and simulated spectrum from $298 \mathrm{~K}$ SCXRD data in red on the bottom; Figure S2: PXRD pattern of 2, with the 298 K PXRD pattern in black on top and simulated spectrum from $155 \mathrm{~K}$ SCXRD data in red on the bottom. No $298 \mathrm{~K}$ SCXRD structure could be obtained; Figure S3. PXRD pattern of 3, with the 298 K PXRD pattern in black on top and simulated spectrum from $298 \mathrm{~K}$ SCXRD data in red on the bottom; Figure S4. TGA analysis of filtered samples of 1; Figure S5. TGA analysis of filtered samples of 2; Figure S6. TGA analysis of filtered samples of 3; Table S1. Crystal data and structure refinement for 1 at $298 \mathrm{~K}$; Table S2. Crystal data and structure refinement for 2 at $155 \mathrm{~K}$; Table S3. Crystal data and structure refinement for 3 at $298 \mathrm{~K}$.

Author Contributions: A.R.C. performed the synthetic, experimental, single crystal X-ray and magnetic studies. C.J.K. assisted in the magnetic studies. M.M.B. and C.E.M. assisted with crystallographic studies. A.R.C., L.F.L. and F.L. prepared the manuscript, and F.L. directed the work.

Funding: This research received no external funding.

Acknowledgments: The research described herein was supported by the Western Sydney University (WSU). The authors acknowledge Richard Wuhrer and the Western Sydney University Advanced Materials and Characterisation facility. The crystallographic data was undertaken on the MX1 beamline of the Australian Synchrotron, Clayton, Victoria, Australia. We thank the Australian Nuclear Science and Technology Organisation (ANSTO) and the Australian Synchrotron for travel support and their staff for assistance. Furthermore, A.R.C. acknowledges the Western Sydney University Masters of research scholarship and AINSE honours scholarship programs.

Conflicts of Interest: The authors declare no conflict of interest.

\section{References}

1. Gütlich, P.; Hauser, A.; Spiering, H. Thermal and optical switching of Iron(II) complexes. Angew. Chem. Int. Ed. 1994, 33, 2024-2054. [CrossRef]

2. Bousseksou, A.; Molnár, G.; Salmon, L.; Nicolazzi, W. Molecular spin crossover phenomenon: recent achievements and prospects. Chem. Soc. Rev. 2011, 40, 3313-3335. [CrossRef] [PubMed]

3. Murray, K.S. The development of spin-crossover research. In Spin Crossover Materials: Properties and Applications; John Wiley \& Sons Ltd.: Oxford, UK, 2013.

4. Halcrow, M.A. Structure:function relationships in molecular spin-crossover materials. In Spin-Crossover Materials: Properties and Applications; John Wiley \& Sons Ltd.: Oxford, UK, 2013. 
5. Kumar, K.S.; Ruben, M. Emerging trends in spin crossover (SCO) based functional materials and devices. Coord. Chem. Rev. 2017, 346, 176-205. [CrossRef]

6. Miyamachi, T.; Gruber, M.; Davesne, V.; Bowen, M.; Boukari, S.; Joly, L.; Scheurer, F.; Rogez, G.; Yamada, T.K.; Ohresser, P.; et al. Robust spin crossover and memristance across a single molecule. Nat. Commun. 2012, 3, 938. [CrossRef] [PubMed]

7. Lefter, C.; Davesne, V.; Salmon, L.; Molnár, G.; Demont, P.; Rotaru, A.; Bousseksou, A. Charge transport and electrical properties of spin crossover materials: Towards nanoelectronic and spintronic devices. Magnetochemistry 2016, 2, 18. [CrossRef]

8. Frisenda, R.; Harzmann, G.D.; Celis Gil, J.A.; Thijssen, J.M.; Mayor, M.; van der Zant, H.S.J. Stretching-induced conductance increase in a spin-crossover molecule. Nano Lett. 2016, 16, 4733-4737. [CrossRef] [PubMed]

9. Harzmann, G.D.; Frisenda, R.; van der Zant, H.S.J.; Mayor, M. Single-molecule spin switch based on voltage-triggered distortion of the coordination sphere. Angew. Chem. Int. Ed. 2015, 54, 13425-13430. [CrossRef] [PubMed]

10. Marchivie, M.; Guionneau, P.; Létard, J.-F.; Chasseau, D. Towards direct correlations between spin-crossover and structural features in Iron(II) complexes. Acta Cryst. B 2003, 59, 479-486. [CrossRef]

11. Gütlich, P.; Garcia, Y.; Goodwin, H.A. Spin crossover phenomena in Fe(II) complexes. Chem. Soc. Rev. 2000, 29, 419-427. [CrossRef]

12. Hostettler, M.; Törnroos, K.W.; Chernyshov, D.; Vangdal, B.; Bürgi, H.-B. Challenges in engineering spin crossover: structures and magnetic properties of six alcohol solvates of Iron(II) tris(2-picolylamine) dichloride. Angew. Chem. Int. Ed. 2004, 43, 4589-4594. [CrossRef] [PubMed]

13. Kahn, O.; Martinez, C.J. Spin-transition polymers: From molecular materials toward memory devices. Science 1998, 279, 44-48. [CrossRef]

14. Steinert, M.; Schneider, B.; Dechert, S.; Demeshko, S.; Meyer, F. Spin-state versatility in a series of $\mathrm{Fe}_{4}[2 \times 2]$ grid complexes: effects of counteranions, lattice solvent, and intramolecular cooperativity. Inorg. Chem. 2016, 55, 2363-2373. [CrossRef] [PubMed]

15. Lochenie, C.; Bauer, W.; Railliet, A.P.; Schlamp, S.; Garcia, Y.; Weber, B. Large Thermal hysteresis for Iron(II) spin crossover complexes with N-(Pyrid-4-Yl)Isonicotinamide. Inorg. Chem. 2014, 53, 11563-11572. [CrossRef] [PubMed]

16. Dankhoff, K.; Lochenie, C.; Puchtler, F.; Weber, B. Solvent influence on the magnetic properties of iron(ii) spin-crossover coordination compounds with 4,4'-dipyridylethyne as linker. Eur. J. Inorg. Chem. 2016, 2016, 2136-2143. [CrossRef]

17. Harding, D.J.; Phonsri, W.; Harding, P.; Gass, I.A.; Murray, K.S.; Moubaraki, B.; Cashion, J.D.; Liu, L.; Telfer, S.G. Abrupt spin crossover in an Iron(III) quinolylsalicylaldimine complex: Structural Insights and solvent effects. Chem. Commun. 2013, 49, 6340-6342. [CrossRef] [PubMed]

18. Duriska, M.B.; Neville, S.M.; Moubaraki, B.; Cashion, J.D.; Halder, G.J.; Chapman, K.W.; Balde, C.; Létard, J.-F.; Murray, K.S.; Kepert, C.J.; et al. A nanoscale molecular switch triggered by thermal, light, and guest perturbation. Angew. Chem. Int. Ed. 2009, 48, 2549-2552. [CrossRef] [PubMed]

19. Wu, X.-R.; Shi, H.-Y.; Wei, R.-J.; Li, J.; Zheng, L.-S.; Tao, J. Coligand and solvent effects on the architectures and spin-crossover properties of (4,4)-connected Iron(II) coordination polymers. Inorg. Chem. 2015, 54, 3773-3780. [CrossRef] [PubMed]

20. Fumanal, M.; Jiménez-Grávalos, F.; Ribas-Arino, J.; Vela, S. Lattice-solvent effects in the spin-crossover of an $\mathrm{Fe}(\mathrm{II})$-based material. The key role of intermolecular interactions between solvent molecules. Inorg. Chem. 2017, 56, 4474-4483. [CrossRef] [PubMed]

21. Milin, E.; Benaicha, B.; El Hajj, F.; Patinec, V.; Triki, S.; Marchivie, M.; Gómez-García, C.J.; Pillet, S. Magnetic bistability in macrocycle-based FeII spin-crossover complexes: Counter ion and solvent effects. Eur. J. Inorg. Chem. 2016, 2016, 5282. [CrossRef]

22. Saureu, S.; de Graaf, C. On the role of solvent effects on the electronic transitions in Fe(II) and Ru(II) complexes. Chem. Phys. 2014, 428, 59-66. [CrossRef]

23. Liu, C.; Zhang, J.; Lawson Daku, L.M.; Gosztola, D.; Canton, S.E.; Zhang, X. Probing the impact of solvation on photoexcited spin crossover complexes with high-precision x-ray transient absorption spectroscopy. J. Am. Chem. Soc. 2017, 139, 17518-17524. [CrossRef] [PubMed] 
24. Herold, C.F.; Shylin, S.I.; Rentschler, E. Solvent-dependent SCO behavior of dinuclear Iron(II) complexes with a 1,3,4-thiadiazole bridging ligand. Inorg. Chem. 2016, 55, 6414-6419. [CrossRef] [PubMed]

25. Phonsri, W.; Harding, P.; Liu, L.; Telfer, S.G.; Murray, K.S.; Moubaraki, B.; Ross, T.M.; Jameson, G.N.L.; Harding, D.J. Solvent modified spin crossover in an Iron(III) complex: phase changes and an exceptionally wide hysteresis. Chem. Sci. 2017, 8, 3949-3959. [CrossRef] [PubMed]

26. Vieira, B.J.C.; Dias, J.C.; Santos, I.C.; Pereira, L.C.J.; da Gama, V.; Waerenborgh, J.C. thermal hysteresis in a spin-crossover FeIII quinolylsalicylaldimine complex, $\mathrm{Fe}^{\mathrm{III}}(5-\mathrm{Br}-\mathrm{Qsal})_{2} \mathrm{Ni}(\mathrm{Dmit})_{2} \cdot$ solv: Solvent effects. Inorg. Chem. 2015, 54, 1354-1362. [CrossRef] [PubMed]

27. Bonnet, S.; Molnár, G.; Sanchez Costa, J.; Siegler, M.A.; Spek, A.L.; Bousseksou, A.; Fu, W.-T.; Gamez, P.; Reedijk, J. Influence of sample preparation, temperature, light, and pressure on the two-step spin crossover mononuclear compound [Fe(Bapbpy)(NCS) ${ }_{2}$ ]. Chem. Mater. 2009, 21, 1123-1136. [CrossRef]

28. Craig, G.A.; Costa, J.S.; Roubeau, O.; Teat, S.J.; Aromí, G. Local coordination geometry and spin state in novel $\mathrm{Fe}^{\mathrm{II}}$ complexes with 2,6-Bis(Pyrazol-3-Yl)Pyridine-Type ligands as controlled by packing forces: Structural correlations. Chem. Eur. J. 2012, 18, 11703-11715. [CrossRef] [PubMed]

29. Wei, R.-J.; Tao, J.; Huang, R.-B.; Zheng, L.-S. Reversible and irreversible vapor-induced guest molecule exchange in spin-crossover compounds. Inorg. Chem. 2011, 50, 8553-8564. [CrossRef] [PubMed]

30. Zhang, W.; Zhao, F.; Liu, T.; Yuan, M.; Wang, Z.-M.; Gao, S. Spin crossover in a series of Iron(II) complexes of 2-(2-Alkyl-2H-Tetrazol-5-Yl)-1,10-Phenanthroline: Effects of alkyl side chain, solvent, and anion. Inorg. Chem. 2007, 46, 2541-2555. [CrossRef] [PubMed]

31. Amoore, J.J.M.; Kepert, C.J.; Cashion, J.D.; Moubaraki, B.; Neville, S.M.; Murray, K.S. Structural and magnetic resolution of a two-step full spin-crossover transition in a dinuclear Iron(II) pyridyl-bridged compound. Chem. Eur. J. 2006, 12, 8220-8227. [CrossRef] [PubMed]

32. Rajadurai, C.; Qu, Z.; Fuhr, O.; Gopalan, B.; Kruk, R.; Ghafari, M.; Ruben, M. Lattice-solvent controlled spin transitions in Iron(II) complexes. Dalton Trans. 2007, 3531-3537. [CrossRef] [PubMed]

33. Bartel, M.; Absmeier, A.; Jameson, G.N.L.; Werner, F.; Kato, K.; Takata, M.; Boca, R.; Hasegawa, M.; Mereiter, K.; Caneschi, A.; et al. Modification of spin crossover behavior through solvent assisted formation and solvent inclusion in a triply interpenetrating three-dimensional network. Inorg. Chem. 2007, 46, 4220-4229. [CrossRef] [PubMed]

34. Chuang, Y.-C.; Liu, C.-T.; Sheu, C.-F.; Ho, W.-L.; Lee, G.-H.; Wang, C.-C.; Wang, Y. New Iron(II) spin crossover coordination polymers $\left[\mathrm{Fe}(\mu-\mathrm{Atrz})_{3}\right] \mathrm{X}_{2} \cdot 2 \mathrm{H}_{2} \mathrm{O}\left(\mathrm{X}=\mathrm{ClO}_{4}{ }^{-}, \mathrm{BF}_{4}{ }^{-}\right)$and $\left[\mathrm{Fe}(\mu-\mathrm{Atrz})(\mu-\mathrm{Pyz})(\mathrm{NCS})_{2}\right] \cdot 4 \mathrm{H}_{2} \mathrm{O}$ with an interesting solvent effect. Inorg. Chem. 2012, 51, 4663-4671. [CrossRef] [PubMed]

35. Leita, B.A.; Neville, S.M.; Halder, G.J.; Moubaraki, B.; Kepert, C.J.; Létard, J.-F.; Murray, K.S. Anion-solvent dependence of bistability in a family of meridional N-Donor-Ligand-Containing Iron(II) spin crossover complexes. Inorg. Chem. 2007, 46, 8784-8795. [CrossRef] [PubMed]

36. Halder, G.J.; Kepert, C.J.; Moubaraki, B.; Murray, K.S.; Cashion, J.D. Guest-dependent spin crossover in a nanoporous molecular framework material. Science 2002, 298, 1762-1765. [CrossRef] [PubMed]

37. Weber, B.; Bauer, W.; Pfaffeneder, T.; Dîrtu, M.M.; Naik, A.D.; Rotaru, A.; Garcia, Y. Influence of hydrogen bonding on the hysteresis width in Iron(II) spin-crossover complexes. Eur. J. Inorg. Chem. 2011, 2011, 3193-3206. [CrossRef]

38. Greenaway, A.M.; Sinn, E. High-spin and low-spin.alpha.-picolylamine Iron(II) complexes. Effect of ligand reversal on spin state. J. Am. Chem. Soc. 1978, 100, 8080-8084. [CrossRef]

39. Ferguson, A.; Squire, M.A.; Siretanu, D.; Mitcov, D.; Mathonière, C.; Clérac, R.; Kruger, P.E. A face-capped $\left[\mathrm{Fe}_{4} \mathrm{~L}_{4}\right]^{8+}$ spin crossover tetrahedral cage. Chem. Commun. 2013, 49, 1597-1599. [CrossRef] [PubMed]

40. Schulte, K.A.; Fiedler, S.R.; Shores, M.P. Solvent dependent spin-state behaviour via hydrogen bonding in neutral FeII diimine complexes. Aust. J. Chem. 2014, 67, 1595-1600. [CrossRef]

41. Dîrtu, M.M.; Neuhausen, C.; Naik, A.D.; Rotaru, A.; Spinu, L.; Garcia, Y. Insights into the origin of cooperative effects in the spin transition of $\left[\mathrm{Fe}\left(\mathrm{NH}_{2} \mathrm{trz}\right)_{3}\right]\left(\mathrm{NO}_{3}\right)_{2}$ : The role of supramolecular interactions evidenced in the crystal structure of $\left[\mathrm{Cu}\left(\mathrm{NH}_{2} \mathrm{trz}\right)_{3}\right]\left(\mathrm{NO}_{3}\right)_{2} \cdot \mathrm{H}_{2} \mathrm{O}$. Inorg. Chem. 2010, 49, 5723-5736. [CrossRef] [PubMed]

42. Costa, J.S.; Rodríguez-Jiménez, S.; Craig, G.A.; Barth, B.; Beavers, C.M.; Teat, S.J.; Aromí, G. Three-way crystal-to-crystal reversible transformation and controlled spin switching by a nonporous molecular material. J. Am. Chem. Soc. 2014, 136, 3869-3874. [CrossRef] [PubMed]

43. Gentili, D.; Demitri, N.; Schäfer, B.; Liscio, F.; Bergenti, I.; Ruani, G.; Ruben, M.; Cavallini, M. Multi-modal sensing in spin crossover compounds. J. Mater. Chem. C 2015, 3, 7836-7844. [CrossRef] 
44. Barrios, L.A.; Bartual-Murgui, C.; Peyrecave-Lleixà, E.; Le Guennic, B.; Teat, S.J.; Roubeau, O.; Aromí, G. Homoleptic versus heteroleptic formation of mononuclear $\mathrm{Fe}(\mathrm{II})$ complexes with tris-imine ligands. Inorg. Chem. 2016, 55, 4110-4116. [CrossRef] [PubMed]

45. Huang, W.; Shen, F.; Zhang, M.; Wu, D.; Pan, F.; Sato, O. Room-temperature switching of magnetic hysteresis by reversible single-crystal-to-single-crystal solvent exchange in imidazole-inspired Fe(II) complexes. Dalton Trans. 2016, 45, 14911-14918. [CrossRef] [PubMed]

46. Galet, A.; Muñoz, M.C.; Real, J.A. Coordination polymers undergoing spin crossover and reversible ligand exchange in the solid. Chem. Commun. 2006, 41, 4321-4323. [CrossRef] [PubMed]

47. Wang, H.; Sinito, C.; Kaiba, A.; Costa, J.-S.; Desplanches, C.; Dagault, P.; Guionneau, P.; Létard, J.-F.; Negrier, P.; Mondieig, D. Unusual solvent dependence of a molecule-based FeII macrocyclic spin-crossover complex. Eur. J. Inorg. Chem. 2014, 2014, 4927-4933. [CrossRef]

48. Lennartson, A.; Southon, P.; Sciortino, N.F.; Kepert, C.J.; Frandsen, C.; Mørup, S.; Piligkos, S.; McKenzie, C.J. Reversible guest binding in a non-porous Fe(II) coordination polymer host toggles spin crossover. Chem. Eur. J. 2015, 21, 16066-16072. [CrossRef] [PubMed]

49. Steinert, M.; Schneider, B.; Dechert, S.; Demeshko, S.; Meyer, F. A Trinuclear Defect-Grid Iron(II) spin crossover complex with a large hysteresis loop that is readily silenced by solvent vapor. Angew. Chem. Int. Ed. 2014, 53, 6135-6139. [CrossRef] [PubMed]

50. Miller, R.G.; Brooker, S. Reversible quantitative guest sensing via spin crossover of an Iron(II) triazole. Chem. Sci. 2016, 7, 2501-2505. [CrossRef] [PubMed]

51. Archer, R.J.; Hawes, C.S.; Jameson, G.N.L.; McKee, V.; Moubaraki, B.; Chilton, N.F.; Murray, K.S.; Schmitt, W.; Kruger, P.E. Partial spin crossover behaviour in a dinuclear Iron(II) triple helicate. Dalton Trans. 2011, 40, 12368-12373. [CrossRef] [PubMed]

52. Šalitroš, I.; Pavlik, J.; Boča, R.; Fuhr, O.; Rajadurai, C.; Ruben, M. Supramolecular lattice-solvent control of Iron(II) spin transition parameters. CrystEngComm 2010, 12, 2361-2368. [CrossRef]

53. Ostermeier, M.; Berlin, M.-A.; Meudtner, R.M.; Demeshko, S.; Meyer, F.; Limberg, C.; Hecht, S. Complexes of click-derived bistriazolylpyridines: Remarkable electronic influence of remote substituents on thermodynamic stability as well as electronic and magnetic properties. Chem. Eur. J. 2010, 16, 10202-10213. [CrossRef] [PubMed]

54. Pelleteret, D.; Clérac, R.; Mathonière, C.; Harté, E.; Schmitt, W.; Kruger, P.E. Asymmetric spin crossover behaviour and evidence of light-induced excited spin state trapping in a dinuclear Iron(II) helicate. Chem. Commun. 2009, 2, 221-223. [CrossRef] [PubMed]

55. Garcia, Y.; Robert, F.; Naik, A.D.; Zhou, G.; Tinant, B.; Robeyns, K.; Michotte, S.; Piraux, L. Spin transition charted in a fluorophore-tagged thermochromic dinuclear Iron(II) complex. J. Am. Chem. Soc. 2011, 133, 15850-15853. [CrossRef] [PubMed]

56. Scott, H.S.; Ross, T.M.; Moubaraki, B.; Murray, K.S.; Neville, S.M. Spin crossover in polymeric materials using schiff base functionalized triazole ligands. Eur. J. Inorg. Chem. 2013, 2013, 803-812. [CrossRef]

57. Craze, A.R.; Sciortino, N.F.; Badbhade, M.M.; Kepert, C.J.; Marjo, C.E.; Li, F. Investigation of the spin crossover properties of three dinulear Fe(II) triple helicates by variation of the steric nature of the ligand type. Inorganics 2017, 5, 62. [CrossRef]

58. Tuna, F.; Lees, M.R.; Clarkson, G.J.; Hannon, M.J. Readily prepared metallo-supramolecular triple helicates designed to exhibit spin-crossover behaviour. Chem. Eur. J. 2004, 10, 5737-5750. [CrossRef] [PubMed]

59. Garcia, Y.; Grunert, C.M.; Reiman, S.; van Campenhoudt, O.; Gütlich, P. The two-step spin conversion in a supramolecular triple helicate dinuclear Iron(II) complex studied by mössbauer spectroscopy. Eur. J. Inorg. Chem. 2006, 2006, 3333-3339. [CrossRef]

60. Cowieson, N.P.; Aragao, D.; Clift, M.; Ericsson, D.J.; Gee, C.; Harrop, S.J.; Mudie, N.; Panjikar, S.; Price, J.R.; Riboldi-Tunnicliffe, A.; et al. MX1: A bending-magnet crystallography beamline serving both chemical and macromolecular crystallography communities at the Australian Synchrotron. J. Synchrotron. Rad. 2015, 22, 187-190. [CrossRef] [PubMed]

61. McPhillips, T.M.; McPhillips, S.E.; Chiu, H.J.; Cohen, A.E.; Deacon, A.M.; Ellis, P.J.; Garman, E.; Gonzalez, A.; Sauter, N.K.; Phizackerley, R.P.; et al. Blu-ice and the distributed control system: software for data acquisition and instrument control at macromolecular crystallography beamlines. J. Synchrotron. Rad. 2002, 9, 401-406. [CrossRef] 
62. Kabsch, W. XDS. Automatic processing of rotation diffraction data from crystals of initially unknown symmetry and cell constants. J. Appl. Crystallogr. 1993, 26, 795-800. [CrossRef]

63. APEX2, version 2014; Bruker AXS Inc.: Madison, WI, USA, 2014. B) SAINT, version 8.34A; Bruker AXS Inc.: Madison, WI, USA, 2014.

64. SADABS, version 2014/5; Bruker AXS Inc.: Madison, WI, USA, 2001.

65. Sheldrick, G. SHELX-2014: Programs for Crystal Structure Analysis; University of Göttingen: Göttingen, Lower Saxony, Germany, 2014.

66. Sheldrick, G.M. Crystal structure refinement with SHELXL. Acta. Cryst. C 2015, 71, 3-8. [CrossRef] [PubMed]

67. Dolomanov, O.V.; Bourhis, L.J.; Gildea, R.J.; Howard, J.A.K.; Puschmann, H. OLEX2: A complete structure solution, refinement and analysis program. J. Appl. Cryst. 2009, 42, 339-341. [CrossRef]

68. Wolff, S.K.; Grimwood, D.J.; McKinnon, J.J.; Turner, M.J.; Jayatilaka, D.; Spackman, M.A. CrystalExplorer, Version 3.1; University of Western Australia: Perth, Western Australia, Australia, 2012.

69. Fatur, S.M.; Shepard, S.G.; Higgins, R.F.; Shores, M.P.; Damrauer, N.H. A synthetically tunable system to control mlct excited-state lifetimes and spin states in Iron(II) polypyridines. J. Am. Chem. Soc. 2017, 139, 4493-4505. [CrossRef] [PubMed]

70. Spackman, M.A.; Jayatilaka, D. Hirshfeld surface analysis. CrystEngComm 2009, 11, 19-32. [CrossRef]

71. McKinnon, J.J.; Jayatilaka, D.; Spackman, M.A. Towards quantitative analysis of intermolecular interactions with hirshfeld surfaces. Chem. Commun. 2007, 37, 3814-3816. [CrossRef]

72. Archer, R.J.; Scott, H.S.; Polson, M.I.J.; Williamson, B.E.; Mathonière, C.; Rouzières, M.; Clérac, R.; Kruger, P.E. Varied spin crossover behaviour in a family of dinuclear Fe(II) triple helicate complexes. Dalton Trans. 2018, 47, 7965-7974. [CrossRef] [PubMed]

73. Li, L.; Craze, A.R.; Akiyoshi, R.; Tsukiashi, A.; Hayami, S.; Mustonen, O.; Bhadbhade, M.; Bhattacharyya, S.; Marjo, C.E.; Wang, Y.; et al. Direct monitoring of spin transition at a high $\mathrm{T}_{1 / 2}$ value in a dinuclear triple-stranded helicate Iron(II) complex through x-ray pho-toelectron spectroscopy. Dalton Trans. 2018, 47, 2543-2548. [CrossRef] [PubMed]

(C) 2018 by the authors. Licensee MDPI, Basel, Switzerland. This article is an open access article distributed under the terms and conditions of the Creative Commons Attribution (CC BY) license (http:/ / creativecommons.org/licenses/by/4.0/). 